УДК 538.971

\title{
TUNGSTEN RECRYSTALIZATION AND CRACKING UNDER ITER-RELEVANT HEAT LOADS
}

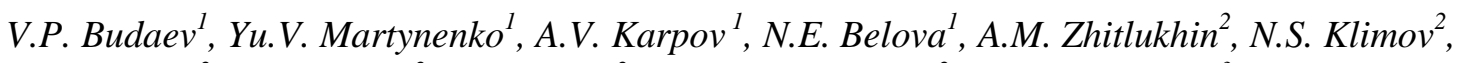 \\ V.L. Podkovyrov", V.A. Barsuk ${ }^{2}$, A.B. Putrik ${ }^{2}$, A.D. Yaroshevskay ${ }^{2}$, R.N. Giniyatulin ${ }^{3}$, V.M. Safronov ${ }^{4,2}$, \\ L.N. Khimchenko ${ }^{4}$
}

\author{
${ }^{I} N R C$ «Kurchatov Institute», Moscow, Russia \\ ${ }^{2}$ SRC RF TRINITI, Moscow Region, Russia \\ ${ }^{3}$ Efremov Institute, St. Petersburg, Russia \\ ${ }^{4}$ Institution «Project center ITER», Moscow, Russia
}

The tungsten surface structure was analyzed after the test in the QSPA-T under heat loads relevant to those expected in the ITER during disruptions. Repeated pulses lead to the melting and the recrystallization of the tungsten surface layer of $\sim 50 \mu \mathrm{m}$ thickness. The recrystallized layer has the same texture as the original structure with the orientation $\langle 100\rangle$ which is normal to the surface, at the same time the grains' sizes in the recrystallized layer are much larger. There is an interface layer between the original structure and the recrystallized layer. The interface layer has a random grains' orientation and $\sim 50 \mu \mathrm{m}$ thickness. The texture of this layer differs considerably from the original tungsten structure. The cracks which are normal to the surface were observed in the recrystallyzed layer as well as the cracks which are parallel to the surface at the depth up to $300 \mu \mathrm{m}$. Such cracks can result in the brittle destruction which is a hazard for the full tungsten divertor of the ITER. The theoretical analysis of the crack formation reasons and a possible consequence for the ITER is given.

Key words: plasma disruption, tungsten, cracks.

PACS: 28.52.Fa, 52.40.H, 52.55.Fa

\section{РЕКРИСТАЛЛИЗАЦИЯ И РАСТРЕСКИВАНИЕ ВОЛЬФРАМА ПРИ ТЕПЛОВЫХ НАГРУЗКАХ, ОЖИДАЕМЫХ В ИТЭР}

\author{
В.П. Будаев ${ }^{1}$, Ю.В. Мартыненко ${ }^{1}$, А.В. Карпов ${ }^{1}$, Н.Е. Белова ${ }^{1}$, А.М. Житлухин ${ }^{2}$, Н.С. Климов ${ }^{2}$, \\ В.Л. Подковыров ${ }^{2}$ В.А. Барсук ${ }^{2}$, А.Б. Путрик, А.Д. Ярошевская ${ }^{2}$, Р.Н. Гиниятулин ${ }^{3}$, В.М. Сафронов, ${ }^{4}$, \\ Л.Н. Химченко ${ }^{4}$
}

\author{
${ }^{1}$ НИЦ «Курчатовский институт», Москва, Россия \\ ${ }^{2}$ ГНЦ РФ ТРИНИТИ, Московская обл., Россия \\ ${ }^{3}$ ФУП «НИИЭФА им. Д.В. Ефремова», С.-Петербург, Россия \\ ${ }^{4}$ Частное учреждение «ИТЭР-Центр», Москва, Россия
}

Исследовался вольфрам после испытаний в КСПУ при тепловых нагрузках, ожидаемых в ИТЭР при срывах. После серии импульсов обнаружены переправление и рекристаллизация вольфрама в слое на глубине до 50 мкм. Рекристаллизованный слой так же, как и исходная структура, имеет текстуру с ориентацией $<100>$ перпендикулярно поверхности, но размеры зёрен в рекристаллизованном слое значительно больше. Между исходной структурой и рекристаллизованным слоем находится переходный слой толщиной $~ 50$ мкм с хаотической ориентацией зёрен. Текстура рекристаллизованного слоя существенно отличается от исходной. Наблюдались нормальные к поверхности трещины, простирающиеся от поверхности до глубины рекристаллизованного слоя, и трещины, параллельные поверхности на глубине до 300 мкм. Такие трещины могут вызвать хрупкое разрушение и быть опасны для полностью вольфрамового дивертора ИТЭР. Даётся теоретический анализ причин образования трещин и возможных последствий срывов в ИТЭР.

Ключевые слова: срыв плазмы, вольфрам, трещины.

\section{INTRODUCTION}

Critical issues for the ITER remain with respect to the reliability of plasma, ELM and disruption control and the consequences of possible tungsten (W) melting by loss of control on the operational behavior of the device [1-3]. The thermal loads to the ITER divertor during disruption is up to the $\mathrm{GW} \cdot \mathrm{m}^{-2}$ — range which corresponds to heat flux factors FHF on the order of several tens of $\mathrm{MW} \cdot \mathrm{m}^{-2} \cdot \mathrm{s}^{-0.5}$. The use of plasma-facing tungsten in fusion devices is discussed to be risked by occurrence of its brittleness at the low temperature and the grain growth at high temperatures.

In experiments on the high power electron beam test facilities [4] it was found that the thermal shock induces crack pattern dependent on the microstructure (grains' shape and size) of the tungsten grade used and on the temperature of targets at the electron beam exposure. The thermal response to intense electron beam pulses 
is not fully identical to a plasma load on the material target, especially related to effects of plasma flux, erosion/deposition conditions, solidification of the melted layer etc. Hence comprehensive studies in plasma facilities are needed to quantify these effects.

Characteristics of droplets ejection from pure tungsten surface and large-scale network of cracks formation were studied on the QSPA-T [5]. Erosion due to a brittle destruction at solidification of melted tungsten layer under heat loads relevant to those expected on the ITER during disruptions has not yet been investigated.

The surface characterization of the tungsten is important for the problem of the deposition [6] and dust production due to a brittle destruction [1-3]. The compatibility of tungsten with beryllium has to be investigated to clarify the effect of the deposition of beryllium eroded from the ITER first wall to divertor plates. To reduce risks of failure, these issues must be clarified as much as possible before tungsten is used in the full-W divertor for the ITER.

Experimental studies using tungsten targets have been performed on the QSPA-T (SRC RF TRINITI) plasma gun. This paper reports the main findings of these experiments.

\section{TUNGSTEN HEAT LOAD EXPERIMENTS ON QSPA-T}

The QSPA-T plasma gun is used for material erosion investigations as well as for the testing of the ITER divertor plasma-facing components under intense transient plasma heat loads [5, 7]. The QSPA-T has been used to expose tungsten targets to energy densities relevant to those expected during the plasma thermal quench phases of disruptions on the ITER.

Targets of Russian grade (RG) B-MП tungsten are of $100 \times 10 \mathrm{~mm}$ and thickness of $2 \mathrm{~mm}$ and more. The industrial technique of rolling is used for the production of this tungsten grade.

The targets were repeatedly exposed in the QSPA-T plasma pulses of $0.5 \mathrm{~ms}$ duration at a heat flux $q \approx 2 \mathrm{MJ} \cdot \mathrm{m}^{-2}$, corresponding to $F_{\mathrm{HF}} \approx 90 \mathrm{MJ} \cdot \mathrm{m}^{-2} \cdot \mathrm{s}^{-0.5}$ and exceeding the melting threshold. The exposed tungsten targets were analyzed post-mortem by means of optical and scanning electron microscopy (SEM) as well by using $X$-ray diffraction technique. A brittleness of tungsten samples may cause some difficulties in metallographic analysis detecting small-scale cracks. Usual approaches to analyze a tungsten structure are (i) SEM analysis of a metallographic section of a sample or (ii) SEM analysis of a metallographic section polished by industrial abrasives. Both techniques are improper. Roughness of a raw metallographic section (i) does not allow obtaining by SEM a micrograph of a sufficient contrast and resolution. A polishing by industrial abrasives (ii) of a metallographic section can lead to a violation of the grain structure and a hiding of small-scale cracks.

We used improved metallographic technique of delicate polishing to detect small-scale cracking in the solidified layer. It allowed us to obtain micrographs with improved resolution of the structure.

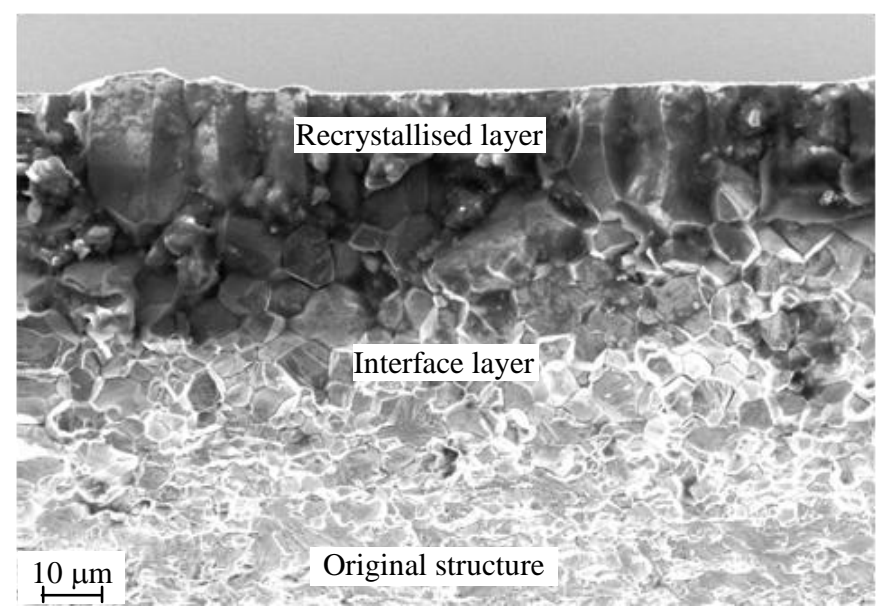

Fig. 1. Metallographic section of the tungsten target after exposure in the QSPA-T $\left(\Delta t=0.5 \mathrm{~ms}, 2 \mathrm{MJ} \cdot \mathrm{m}^{-2}, F_{\mathrm{HF}} \approx 90 \mathrm{MJ} \cdot \mathrm{m}^{-2} \cdot \mathrm{s}^{-0.5}\right), N=2$ pulses

Typical metallographic section is shown in Fig. 1 for the RG-target after exposition during two pulses.

There is a large-scale columnar crystallites structure on the surface. The recrystallized thickness of the target surface is up to $\sim 40-50 \mu \mathrm{m}$ (Fig. 1, 2). Brittle destruction due to cracks (see Fig. 2) in the solidified layer can produce dust particles of sub-microns scale size. Burning plasma conditions requires low core $\mathrm{W}$ concentrations $\left(<10^{5}\right)$. Hence a contamination of burning plasma by small-scale $\mathrm{W}$ dust particles is a critical issue of the solidified layer brittle destruction.

Interface layer is observed between original basic structure and recrystallised layer, Fig. 1, 2. The thickness of the interface layer is of the same order as the recrystallized layer. 
Very similar behavior has been observed for the RG tungsten target surface after exposure in the QSPA-T during 50 pulses (Fig. 3). Except the cracks in recrystalized layer which are normal to the surface, there are large-scale cracks along the surface situated deep in the body (exceeding $\sim 300 \mu \mathrm{m}$ ).

The texture with preferable orientation $\langle 100\rangle$ which is normal to the surface is found in the original basic structure and the recrystallized layer of the targets, Fig. 4. The grains in the recrystallized layer have sizes of $\sim 10 \times 50 \mu \mathrm{m}$, whereas the grain size in original structure is $\sim 1 \mu \mathrm{m}$. The interface layer (between recrystallized layer on the surface and basic structure) is characterized by random oriented smallscale crystallites of $\sim 3-5 \mu \mathrm{m}$ with no elongation (see Fig. 1, 2). Diffraction-peak broadening (see Fig. 4) shows the tensile stress along the surface

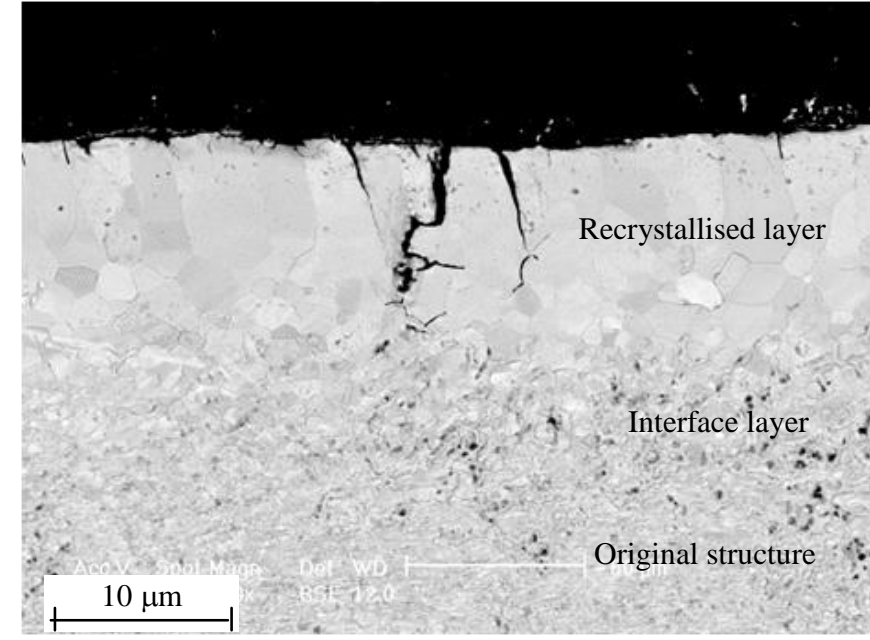

Fig. 2. Metallographic section of the tungsten target after exposure in the QSPA-T $\left(\Delta t=0.5 \mathrm{~ms}, 2 \mathrm{MJ} \cdot \mathrm{m}^{-2}, F_{\mathrm{HF}} \approx 90 \mathrm{MJ} \cdot \mathrm{m}^{-2} \cdot \mathrm{s}^{-0.5}\right), N=2$ pulses corresponding $\Delta \rho / \rho=0.2-0.5($ see $(1))$
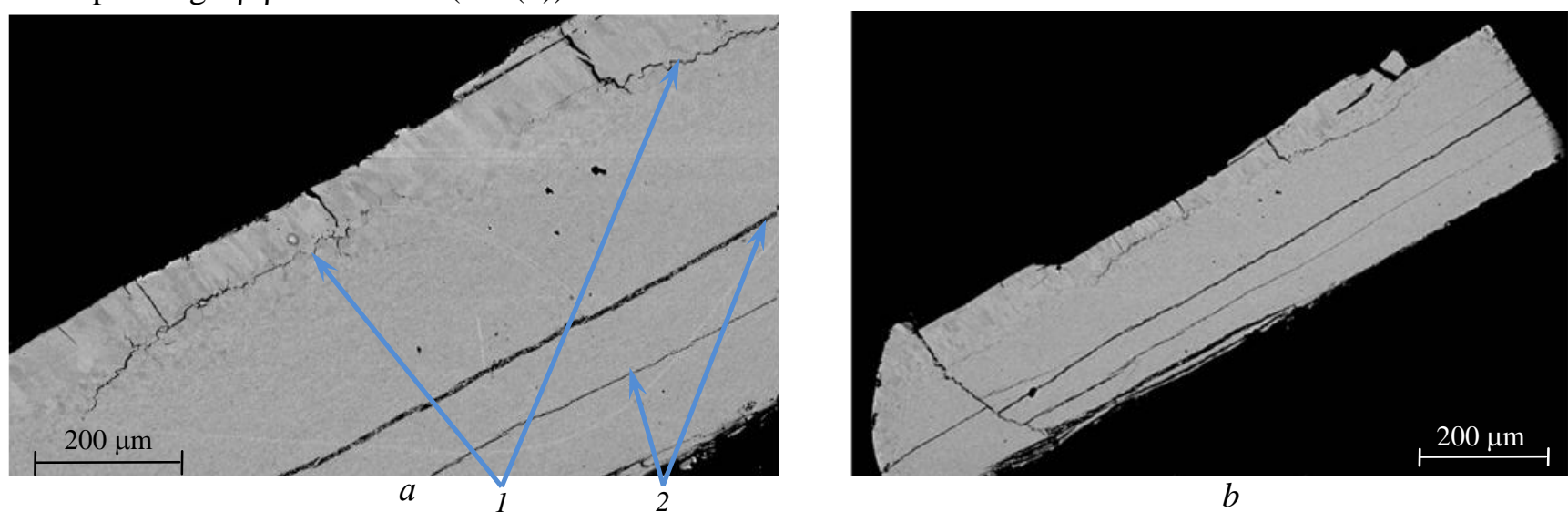

Fig. 3. Metallographic sections of the tungsten target after exposure in the QSPA-T $\left(\Delta t=0.5 \mathrm{~ms}, 2 \mathrm{MJ} \cdot \mathrm{m}^{-2}, F_{\mathrm{HF}} \approx 90 \mathrm{MJ} \cdot \mathrm{m}^{-2} \cdot \mathrm{s}^{-0.5}\right)$, $N>50$ pulses: 1 - cracks along interface layer from the recrystallization of the surface layer; 2 - cracks deep in the body due to strong heating of the targets and original defects from the production techniques of rolling $(a) ; b-$ deep transversal crack is seen

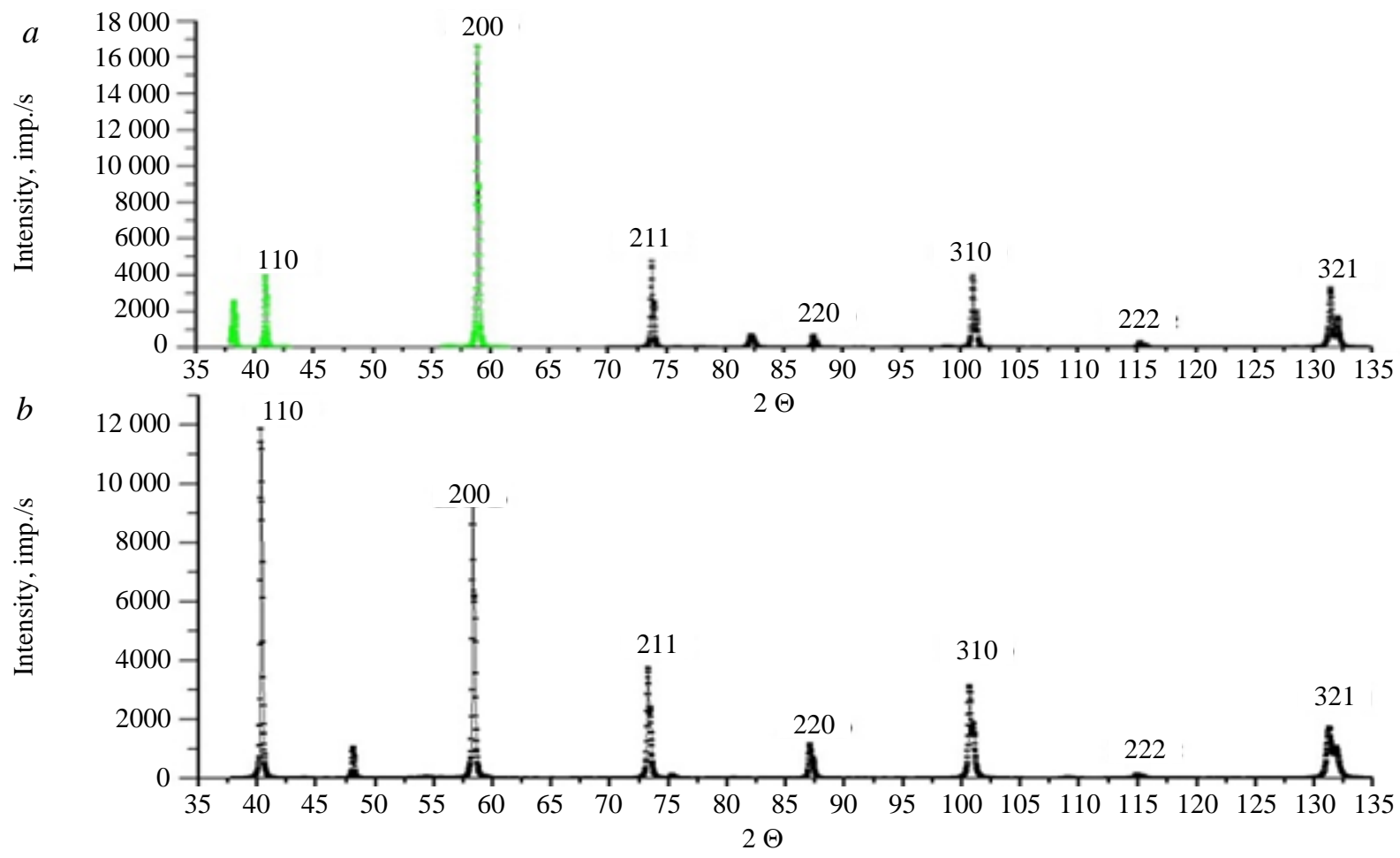




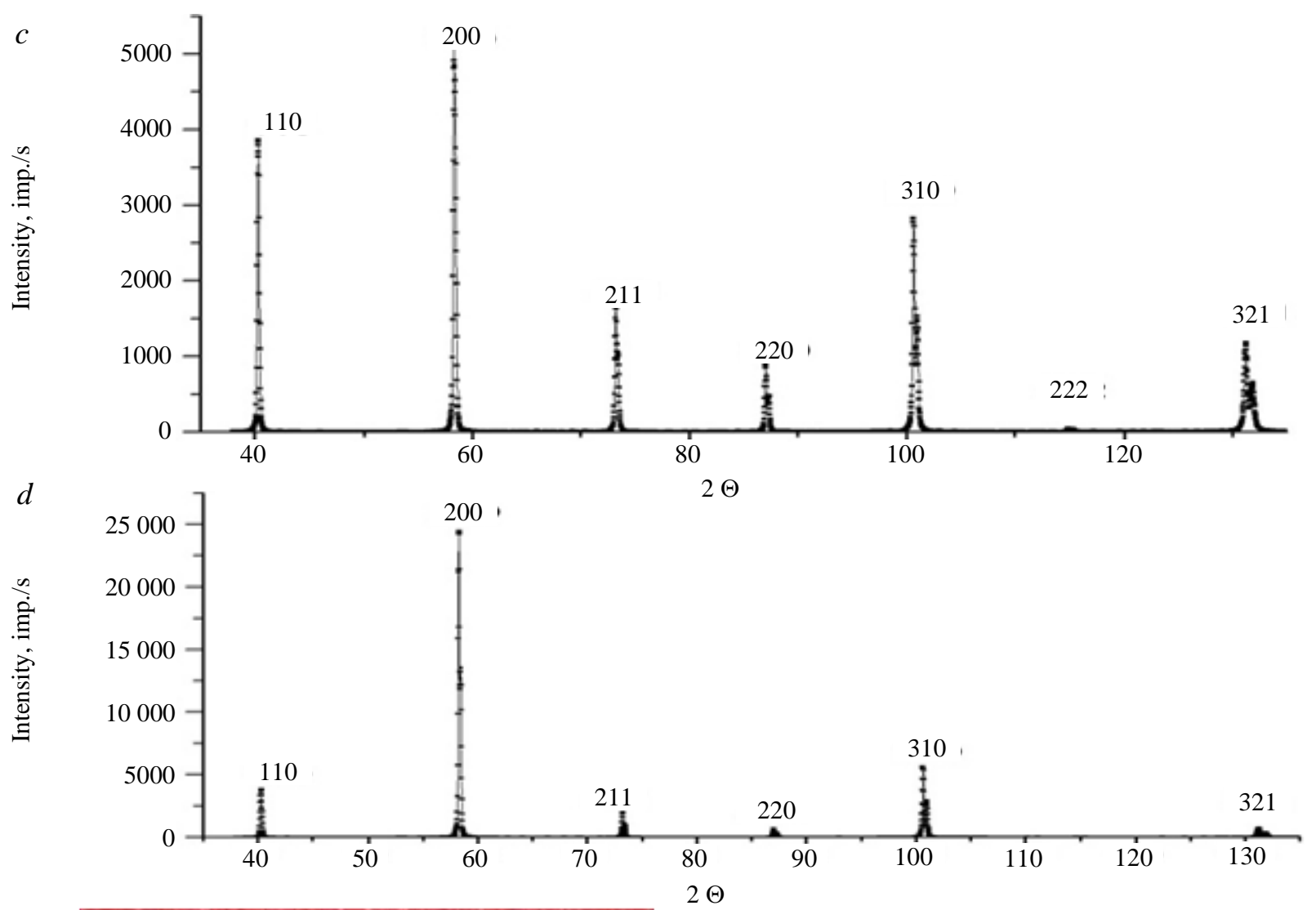

$e$

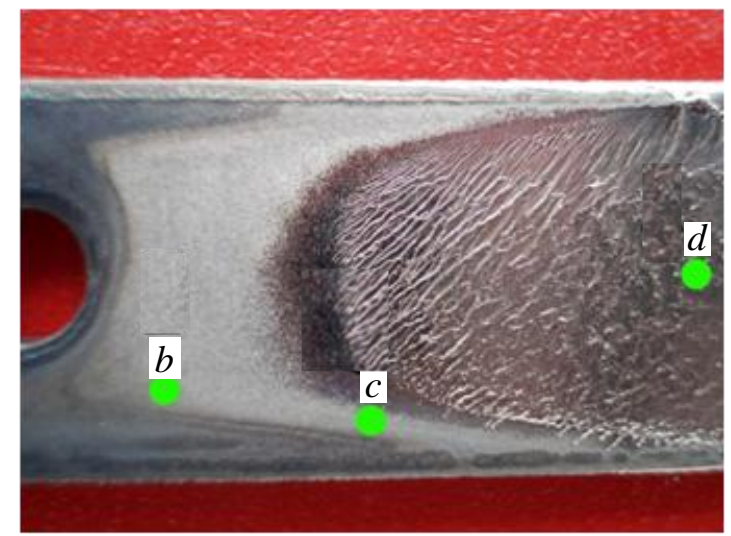

Fig. 4. $X$-ray diffraction spectra: intensity vs scattering angle. Texture is identified by diffraction peaks. $X$-ray tube uses a copper anode: $a$ - original tungsten structure; $b$ - boundary of recrystallized layer; $c$ - boundary of recrystallized layer; $d$ - recrystallized layer; $e$ - view of tungsten target after exposure in the QSPA-T with indication of $X$-ray diffraction locations $b, c, d$

\section{DISCUSSION}

There are two kinds of reasons of the metal cracking at a pulsed thermal load:

i) the stress arising at the solidification of the melted layer;

ii) the stress arising at the recrystallization of the heated layer.

In the case (i), the melted material has a lower density than crystallized ones. The time of the liquid relaxation due to the fluid dynamic movement $t_{v} \approx R^{2} / v$ ( $v$ is the kinematic viscosity, $R$ is the size of the melted spot) is much higher than the cooling time $t<h^{2} / \chi$ ( $h$ is the thickness of melted layer, $\chi$ is the thermal conductivity). Therefore after the solidification in the layer the residual tensile stress remains

$$
\sigma=K \Delta \rho / \rho,
$$

where $K=E /(1-\mu)$ is the compressibility modulus, $E$ is the elasticity modulus, $\mu$ is the Poisson coefficient, $\rho$ is the material density, $\Delta \rho$ is the density difference in solid and liquid phase.

In the case (ii), a longitudinal tensile stress in the recrystalized layer is caused by a lower longitudinal size of new crystal grains as compare with original grain sizes. It occurs from the recrystallization at elevated temperature $\mathrm{T}$ when compressive stress exists 


$$
\sigma=K \alpha \Delta T,
$$

where $\alpha$ is the thermal expansion coefficient, $\Delta T \approx T-T_{0}, T$ is the temperature of the heated layer, $T_{0}$ is the original temperature. A point defects diffusion and a dislocation movement occur during the recrystallisation and the compressive stress pushes the mobile material component out the layer. Note that the crystallization occurs at the solidification of the melted layer. But the recrystallization arises also at a temperature below melting temperature $T_{\mathrm{m}}$. According Bochvar, the temperature of the recrystallization is $T_{\text {rer }}=k T_{\mathrm{m}}, k<1$ and decreases with the crystal disordering. Thus after the cooling and the recrystallization completion the residual tensile stress remains in the recrystallized layer. This stress can reach the value of (2) if at the recrystallization the compressive stress is not removed by diffusion processes and the dislocation movement. But more probably the residual stress is lower.

Thus there are two cases of longitudinal tensile stress appearance in the surface layer of metal after the pulsed thermal load. This stress can results in crack appearance being normal to the surface.

Taking into account Griffith criterion that a crack grows at uniform tensile stress if $L>L_{\mathrm{cr}}$, where $L$ is crack's length and the critical $L_{\mathrm{cr}}$ :

$$
L_{\mathrm{cr}}=4 \gamma E /\left[\pi\left(1-\mu^{2}\right) \sigma^{-2}\right]
$$

where $\gamma$ is the surface energy.

If the crack's length is $L<L_{\mathrm{cr}}$ the crack will stick. To create such a kind of the crack the energetic threshold $\varepsilon=2 \gamma L_{\mathrm{cr}}^{2}$ has to be overcome. The rough estimation gives $L_{\mathrm{cr}} \approx 10^{-9}-10^{-10} \mathrm{~m}, \varepsilon \approx 10 \mathrm{eV}$. In case of some structure irregularity (such as inclusion, a grain with an acute angle) of a small size $r$ the additional stress $\gamma / r$ exists within this angle. Thus the cracks being normal to the surface appear between grains.

Another reason of the crack is a lower tensile strength between grains. The crack being normal to the surface can propagate deeper than recrystalized layer with the tensile stress along the surface. Actually the stressed surface layer can be considered as a source of concentrated force (per unit of cross section area) $f=\sigma h$ for the crack below the tensile layer. In this case length of the crack is [9]

$$
L=f^{2}(1-\mu) / \pi \gamma E=\sigma^{2} h^{2}(1-\mu) / \pi \gamma E .
$$

We estimate the maximal tensile stress

$$
\sigma=K \alpha\left(T_{\mathrm{m}}-T_{0}\right)
$$

$T_{\mathrm{m}}$ is the melting temperature. Hence cracks in previously heated (higher $T_{0}$ ) sample are shorter. Thickness of the melted layer and thickness of the heated layer depend on power flux $q$ as $h \sim q^{1 / 2}$. Thus length of cracks being normal to surface is $L \sim q$.

The length of transversal cracks depends on initial strength of the material and in some weak places can be much longer then melted and recrystallized layer. Such crack can grow at repetitive plasma pulses due to metal fatigue.

The deep cracks along the surface (see Fig. 3) seem to be the most dangerous. The peer examination of tested samples shows that they are bent toward the back (no radiated) side. The curvature radius of the samples measured in a plane along the highest size of the sample plate is within the range of $2.6 \mathrm{~m}<R<9 \mathrm{~m}$. Assuming that the curvature is a sequence of tensile stress $\sigma$ in the surface layer with given thickness $h$, one can estimate $\sigma$ to explain the observed curvature. For $h \ll d$ ( $d$ is the samples thickness)

$$
1 / R=6 h / d^{2} \sigma(1-\mu) / E .
$$

From (6) for measured $R$ and $h=50 \mu \mathrm{m}$ one receive $\sigma \approx(1-3) 10^{-3} E$.

A bending of samples is driven by the force $F=f \ell(\ell=10 \mathrm{~mm}$ is the width of the sample) which constricts the both ends of the sample plate. According to [9] the bending occurs if

$$
F>E I / D^{2}=E \ell d^{3} / 12 D^{2},
$$

where $D$ is the length of the highest plate side, $D=100 \mathrm{~mm}, I=\ell d^{3} / 12$ is the plate moment of inertia. From (7) one receive bending criteria $\sigma / E>\sim 10^{-3}$. 
Criterion of bending (7) shows that thick samples (large $d$ ) will not bend. Certainly any thick W tiles will not bend under the same conditions.

The plate bending is the reason of the longitudinal crack formation. Really longitudinal crack occurs in the region where the tensile stress being normal to the surface exists. In the recrystalized layer the tensile stress is parallel to the surface $\left(\sigma_{x x}>0\right)$ and the normal stress component $\sigma_{z z}=-\sigma_{x x} \mu /(1-\mu)$ is compressive and cannot create a longitudinal crack. There are the tensile longitudinal stress $\sigma_{x x}>0$ and the compressive normal stress component $\sigma_{z z}$ in the back part of the undisturbed part of the bent plate (toward which the bending occurs). At the same time, there are the compressive longitudinal stress $\sigma_{x x}<0$ and the tensile normal stress component $\sigma_{z z}$ in the plasma faced surface of the bent undisturbed plate. Thus the plasma faced side deeper than the heated layer is the sole part of the bent plate which has the tensile normal stress component $\sigma_{z z}$. Longitudinal cracks can appear only in this part of bent sample. In bending absence no longitudinal crack is possible.

Therefore longitudinal cracks are possible only in sufficiently thin targets and are not expected in W tiles of the ITER.

\section{CONCLUSIONS}

Targets of Russian grade B-MП tungsten have been investigated after the test in the QSPA-T plasma gun with energy densities relevant to those expected during the plasma thermal quench phases of disruptions on the ITER.

The targets were repeatedly exposed in plasma pulses of $0.5 \mathrm{~ms}$ duration at a heat flux $q \approx 2 \mathrm{MJ} \cdot \mathrm{m}^{-2}$ exceeding the melting threshold. Large-scale columnar crystallites of the recrystallized layer on the surface were observed. The recrystallized layer thickness of the target surface is up to $\sim 40-50 \mu \mathrm{m}$. The recrystallized layer has the same texture as the original structure with the orientation $\langle 100\rangle$ which is normal to the surface, at the same time the grains' sizes in the recrystallized layer are much larger. The interface layer is observed between the original basic structure and the recrystallised layer. The interface layer has a random grains' orientation and $\sim 50 \mu \mathrm{m}$ thickness. The texture of this layer differs considerably from the original tungsten structure.

A transient power impact will lead to a surface cracking and a tungsten embrittlement. The brittle destruction of the recristallyzed layer can produce dust particles of sub-microns scale size which deteriorate the operational performance of the device. Large-scale cracks along the surface situated deep in the body (exceeding $\sim 300 \mu \mathrm{m}$ ) have been observed.

Theoretical analysis of the crack formation and possible consequences for the ITER are given. There are two mechanisms of metal cracking at pulsed thermal load: (1) the stress arising from a solidification of the melted layer and (2) the stress at a recrystallization of the heated layer. A longitudinal tensile stress in the recrystalized layer is caused by a lower longitudinal size of new crystal grains as compare with original grain sizes. The analysis shows that longitudinal cracks are possible only in sufficiently thin targets and are not expected in W tiles of the ITER. Multiple repetitive pulses can produce transversal cracks of very large depth. One can note that saturating hydrogen retention in tungsten can result in additional embrittlement and enhanced destruction of tungsten plates under transient heat loads.

To provide a complete set of material data including physical and mechanical characteristics of tungsten in conditions relevant to the ITER disruptions and ELMs, further detailed experimental tests in plasma facilities are needed.

Acknowledgements: the work was supported by the Rosatom. 


\section{REFERENCES}

1. Pitts R.A., Bazylev B., Carpentier S., Escourbiac F., Hirai T., Komarov V., Kukushkin A.S., Merola M., Mitteau R., Stangeby P.C. A full tungsten divertor for ITER: physics issues and design status. — J. of Nuclear Materials, 2013 (in press).

2. Philipps V. Tungsten as material for plasma-facing components in fusion devices. - J. of Nuclear Materials, 2011, vol. 415, S2-S9.

3. Shimada M., Pitts R., Loarte A., Campbell D.J., Sugihara M., Mukhovatov V., Kukushkin A., Chuyanov V. ITER research plan of plasma - wall interaction. - J. of Nuclear Materials, 2009, vol. 390391, pp. 282-285.

4. Linke J., Loewenhoff T., Massaut V., Pintsuk G., Ritz G., Rodig M., Schmidt A., Thomser C., Uytdenhouwen I., Vasechko V., Wirtz M. Performance of different tungsten grades under transient thermal loads. — Nucl. Fusion, 2011, vol. 51 p. 073017 (6 p.).

5. Klimov N. et al. - J. Nucl. Mater., 2011, vol. 415, S59.

6. Budaev V.P., Khimchenko L.N. Fractal growth of deposited films in tokamaks. - Physica A, 2007, vol. 382, pp. 359-377.

7. Klimov N. et al. - J. Nucl. Mater., 2009, vol. 390-391, pp. 721-726.

8. Martynenko Yu.V., Moskovkin P.G. On droplet erosion of metals under disruption in tokamaks. VANT. Ser. Termoyadernyi sintez (Problems of Atomic Science and Technology. Ser. Thermonuclear Fusion), 2000, vol. 1, pp. 65-69 (in Russian).

9. Landau L.D., Lifshitz E.M. — Theory of Elasticity, 1986, vol. 7 (3rd ed.). Butterworth—Heinemann.

\section{AUTHORS}

Budaev V.P. NRC “Kurchatov Institute”, pl. Kurchatova 1, 123182 Moscow, Russia; Budaev_VP@nrcki.ru

Martynenko Yu.V. NRC "Kurchatov Institute", pl. Kurchatova 1, 123182 Moscow, Russia; Martynenko_YV@nrcki.ru

Karpov A.V. NRC “Kurchatov Institute”, pl. Kurchatova 1, 123182 Moscow, Russia

Belova N.E NRC “Kurchatov Institute”, pl. Kurchatova 1, 123182 Moscow, Russia

Zhitlukhin A.M State Research Center of Russian Federation Troitsk Institute for Innovation \& Fusion Research, ul. Pushkovykh 12, 142190 Troitsk, Moscow, Russia

Klimov N.S. State Research Center of Russian Federation Troitsk Institute for Innovation \& Fusion Research, ul. Pushkovykh 12, 142190 Troitsk, Moscow, Russia

Podkovyrov V.L. State Research Center of Russian Federation Troitsk Institute for Innovation \& Fusion Research, ul. Pushkovykh 12, 142190 Troitsk, Moscow, Russia

Barsuk V.A. State Research Center of Russian Federation Troitsk Institute for Innovation \& Fusion Research, ul. Pushkovykh 12, 142190 Troitsk, Moscow, Russia

Putrik A.B. State Research Center of Russian Federation Troitsk Institute for Innovation \& Fusion Research, ul. Pushkovykh 12, 142190 Troitsk, Moscow, Russia

Yaroshevskay A.D. State Research Center of Russian Federation Troitsk Institute for Innovation \& Fusion Research, ul. Pushkovykh 12, 142190 Troitsk, Moscow, Russia

Giniyatulin R.N. Efremov Scientific Research Institute of Electrophysical Apparatus, pos. Metallostroy, Doroga na Metallostroy 3, 196641 St. Petersburg, Russia

Safronov V.M. Institution «Project center ITER», pl. Kurchatova 1, 123182 Moscow, Russia 
Khimchenko L.N. Institution «Project center ITER», pl. Kurchatova 1, 123182 Moscow, Russia

Received 10 June 2013

Problems of Atomic Science and Technology Ser. Termoyadernyi sintez, 2013, vol. 36, issue 3, pp.53-60 